[Agr. Biol. Chem., Vol. 35, No. 12, p. 1852 1859, 1971]

\title{
Studies on the Ventilation in Submerged Fermentations
}

\section{Part II. Quantitative Studies on the Dissolution and Dissociation of Carbon Dioxide in Cultured System ${ }^{\dagger}$}

\author{
By Ayaaki Ishizaki, Yoshio Hirose and Teruo SHIro \\ Central Research Laboratories of Ajinomoto Co. Inc., \\ Kawasaki, Japan \\ Received May 10, 1971
}

\begin{abstract}
Quantitative studies on the dissolution and dissociation of carbon dioxide in a cultured system were made. The inosine fermentation and the glutamic acid fermentation were employed for this study. According to the results obtained in this experiment, the quantity of dissociated carbonic acid in cultured liquid was given by Henderson-Hasselbalch's equation with experimental $\mathrm{p}^{\prime}$. The method for the direct determination of bicarbonate ion concentration was also investigated. The Warburg direct method gave a satisfactory result for this purpose.
\end{abstract}

In the previous paper," the formula of dissolved and dissociated carbon dioxide in a model system has been investigated. At physiological $\mathrm{pH}$ values, which were in the range of $6 \sim 8$, carbon dioxide in liquid phase was present in the molecular form whose quantity was expressed in the function of Bunsen's absorption coefficient (or Henry's constant for carbon dioxide) and in the dissociated form whose quantity was indicated by Henderson-Hasselbalch's equation for weak acids. The other forms resulting from the dissolution and dissociation of carbon dioxide were carbonic acid and carbonate ion but the quantities of both forms were negligibly small.

The rule of the dissociation of carbon dioxide was preserved in the model liquid system and the quantitative studies of the interconvertion of carbon dioxide and bicarbonate ion proved the validity of Henderson-Hasselbalch's law

$\dagger$ This paper was presented at the Meeting of Agricultural Chemical Society of Japan held in Tokyo, Japan on 8, Nov., 1970.

1) A. Ishizaki, H. Shibai, Y. Hirose and T. Shiro, Agr. Biol. Chem., 35, 1733 (1971) in the phosphate buffer and other model liquid. As far as cultured broth was concerned, it was assumed that the dissolution and dissociation of carbon dioxide proceeded during the preparation of sample and the operation for the determination of carbon dioxide unless an appropriate countermeasure was applied.

Taking into account the difficulties for the determination of the quantities of bicarbonate ions in cultured liquid, it was necessary to study how to reserve all the bicarbonate ions in broth which is in a state of equilibrium of the dissolution and dissociation of carbon dioxide in the fermentor. It was because the quantities of dissolved carbon dioxide and dissociated bicarbonate ions might undergo changes depending upon the differences of the partial pressure of carbon dioxide between the inside and the outside of the culturing vessel, and also depending upon the $\mathrm{pH}$ change due to accumulation or consumption of organic acids in cultured broth.

Special care had, therefore, to be taken for the method of sample preparation and sample preservation. To remove living cells immediately after the sampling operation was 
considered to be a satisfactory method to fix the equilibrium state of the dissociation of carbonic acid to the sample solution. Centrifugal separation and filtration could be applicable to this purpose. Filtration seemed to have great advantages over the centrifugation, under consideration of the convenience of the operation. According to the experimental results, the Millipore Filter with a micro syringe filter holder was found to be a satisfactory apparatus. This syringe was able to connect to an injection needle for sampling of broth inserted to the culturing vessel. Living cells in cultured broth were instantaneously filtered and the respiration was almost immediately ceased. The errors on the determination of bicarbonate ions caused by the evolution of carbon dioxide and the variation of $\mathrm{pH}$ due to the continuing respiration after the filtration should be negligibly small.

In order to know the absolute amount of the dissolved carbon dioxide, it was necessary to resolve the problem how to determine Bunsen's absorption coefficient in the cultured liquid. For this purpose, the Warbung manometry was also available using hydrochloric acid as a carbon dioxide evolving agent and barium hydroxide solution as a reagent for the fixation of gaseous carbon dioxide in the sample solution. The gaseous carbon dioxide was completely absorbed by a single operation of pouring the sample solution into the barium hydroxide solution and all of the absorbed carbon dioxide was recovered by the Warburg manometry.

\section{M.ATERIALS AND METHODS}

Microorganisms employed in this study were Brevibacterium lactofermentum No. $2256^{2}$ and Bacillus subtilis sp." Cultivations of these microorganisms were performed in the media of the following compositions.

2) S. Okumura, R. Tsugawa, T. Tsunoda, K. Kono, S. Matsui, N. Miyachi Nippon Nogeikagaku Kaishi, 36, 141 (1962).

3) R. Aoki, J. Gen. Appl. Microbiol., 9, 397 (1963).
The first medium for Brevibacterium lactofermentum was the hydrolyzed liquid of sweet potato starch containing $10 \%$ of glucose, $\mathrm{KH}_{2} \mathrm{PO}_{4} 0.1 \%, \mathrm{MgSO}_{4}$. $7 \mathrm{H}_{2} \mathrm{O} 0.04 \%, \mathrm{FeSO}_{4} \cdot 7 \mathrm{H}_{2} \mathrm{O} 0.001 \%$, Ajieki (aqueous solution of soy bean meal, $20 \mathrm{~g}$ of nitrogen per liter) $0.75 \mathrm{ml} / \mathrm{dl}$, thiamine- $\mathrm{HCl} 100 \gamma /$ liter, biotin $3 \gamma /$ liter; the second for Bacillus subtilis was the starch hydrolyzate containing $8 \%$ of glucose, $\mathrm{KCl} 2.10^{\circ}$, $\mathrm{KH}_{2} \mathrm{PO}_{4} 0.050, \quad \mathrm{MgSO}_{4} \cdot 7 \mathrm{H}_{2} \mathrm{O} 0.04,0, \mathrm{FeSO}_{4} \cdot 7 \mathrm{H}_{2} \mathrm{O}$ $0.0010^{\circ}, \mathrm{MnSO}_{4} \cdot 5 \mathrm{H}_{2} \mathrm{O} 0.001{ }^{\circ}$, ribonucleic acid (purity $80.6) 0.080^{\circ}$, separately sterilized solution composed of Ajieki $4 \mathrm{ml} / \mathrm{dl}$ and $d l$-methionine $30 \mathrm{mg} / \mathrm{dl}$ in order to prevent a growth of inhibitory materials to the fermentation by the amino-sugar reaction during sterilization.

Cultivation of those bacteria was performed in a glass made jar fermentor with the $\mathrm{pH}$ controlling means using gaseous ammonia according to the method of Kobayashi et al.4

Determination of the bicarbonate concentration of the centrifuged liquid was carried out by the gasexchanged Warburg manometry described in the previous paper. Determination of bicarbonate ion in the filtered sample was performed by the Warburg direct method and this method was also applied to the cultured sample without filtration. A fairly good approximation was obtained among the results of the gas-exchanged Warburg manometry for the centrifuged sample, the Warburg direct method for the filtered sample and the Warburg direct method for the sample without filtration.

Bunsen's absorption coefficient for carbon dioxide was measured by the Warburg manometry using hydrochloric acid solution instead of the titration with the phenolphthalein indicator.

According to the equilibrium constant between carbon dioxide and carbonic acid, the amount of carbonic acid would be one thousandth part of the dissolved carbon dioxide as shown in the following equation. 5 :

$$
\frac{\left[\mathrm{H}_{2} \mathrm{CO}_{3}\right]}{\left[\mathrm{CO}_{2}\right]}=10^{-3}
$$

Changing the above formula using the first stage dissociation constant of carbonic acid, ${ }^{61}$ the equation

4) K. Kobayashi, S. Ikeda, A. Ishizaki, Y. Hirose and T. Shiro, Meeting of Agr. Chem. Soc. of Japan at Kyoto (oral) 17, Oct. 1970.

5) F. J.W. Roughton, J. Am. Chem. Soc., 63, 1930 (1941).

6) A. G. Sykes, Kinetics of Inorganic Reactions, Pergamon Press (Oxford) p. 272, 1966. 
yields

$$
\frac{\left[\mathrm{HCO}_{3}^{-}\right]}{\left[\mathrm{CO}_{2}\right]}=\frac{2.5 \times 10^{-4}}{\left[\mathrm{H}^{+}\right]}
$$

It shows that the fraction of bicarbonate ion over carbon dioxide can be expressed in the function of hydrogen ion concentration $(\mathrm{pH})$.

Consequently, $\mathrm{pH}$ values at which the concentration of bicarbonate might be smaller than one thousandth part of the concentration of dissolved carbon dioxide will be given as the following equation.

$$
\frac{2.5 \times 10^{-7}}{\mathrm{H}^{+}}<10^{-3}
$$

By the transposition of the above equation, the resolution of $\left[\mathrm{H}^{+}\right]$should be given as follows.

$$
\left[\mathrm{H}^{+}\right]>2.5 \times 10^{-4}
$$

$\mathrm{pH}$ below 3.60 is therefore a satisfactory value in order to reduce a quantity of bicarbonate ion formed by the first stage dissociation of carbon dioxide to trace amounts.

In the second stage dissociation of carbon dioxide, ${ }^{7}$ the following equation is yielded by the transposition of the term of the hydrogen ion concentration.

$$
\frac{\left[\mathrm{CO}_{3}=\right]}{\left[\mathrm{CO}_{2}\right]}=\frac{15 \times 10^{-18}}{\left[\mathrm{H}^{+}\right]^{2}}
$$

$\mathrm{pH}$ is given by the same procedure as stated above, and equations can be expressed as follows.

$$
\begin{gathered}
\frac{15 \times 10^{-18}}{\left[\mathrm{H}^{+}\right]^{2}}<10^{-3} \\
{\left[\mathrm{H}^{+}\right]>\sqrt{15 \times 10^{-12}}}
\end{gathered}
$$

$\mathrm{pH}$ below 6.90 is obtained for the conditions that the quantity of carbonate ion is small enough in comparison with the quantity of carbon dioxide in liquid phase. As far as $\mathrm{pH}$ value of sample solution is less than approximately 4.0, a great part of dissolved carbon dioxide is present in the gaseous form and dissociation of carbon dioxide can be neglected. The saturation with carbon dioxide gas for the sample preparation has therefore been performed under the condition of $\mathrm{pH}$ value less than 4.0 in order to make the dissociation of carbon dioxide smaller.

The Bunsen's absorption coefficient for carbon

7) E. J. King, "Acid-Base Equilibria," The International Encyclopedia of Physical Chemistry and Chemical Physics, Vol. 4, Pergamon Press, Oxford, 1965. dioxide can be determined by the recovery of carbon dioxide from barium hydroxide solution using the Warburg manometry.

The purification and reservation of decarbonized pure water were followed to the method described previously.

The treatment of sodium bicarbonate crystal was also done by the previous method.

\section{RESULTS AND DISCUSSIONS}

1) Bunsen's absorption coefficient in cultured broth

The titration method was reported by Etinne and Mather ${ }^{8}$ and also by Stewart, Munjal and Quiring. ${ }^{9 \prime}$ In this method hydrochloric acid was used with the phenolphthalein indicator. This method gave a satisfactory result on pure water and data showed the entire agreement with Bunsen's absorption coefficient for carbon dioxide listed in the International Critical Table. This method, however, could not be applied to the cultured system because the strong buffer capacity of fermentation medium and cultured liquid made invisible change of the color of the indicator. The manometric method was therefore developed to determine the amount of carbon dioxide evolved from barium carbonate precipitate. Bunsen's absorption coefficient $\alpha$ is given by the following equation,

$$
\alpha=\frac{\left(\mathrm{CO}_{2}\right) \times 22.4 \times 760 \times 100}{\left(\mathrm{P}_{\mathrm{atm}}-\mathrm{P}_{\mathrm{H}_{2}} \mathrm{O}\right) \times \mathrm{CO}_{2} \%}
$$

where $\left(\mathrm{CO}_{2}\right)$ is the molarity of dissolved carbon dioxide determined by the Warbung method, $\mathrm{CO}_{2}, \%$ is the concentration of carbon dioxide in gas phase, $P_{a+m}$ is the atmospheric pressure or the total pressure of the absorption vessel, $\mathrm{P}_{\mathrm{H}_{2} \mathrm{O}}$ is the partial pressure of water at the temperature of the absorption vessel.

The result as shown in Table I gave a satisfactory agreement between the titration method and the manometry in pure water

8) F. S. Etinne and E. R. Mather, J. Assoc. Offic. Agr. Chem., 39, 844 (1956),

9) P. B. Stewart, P. K. Munjal and F. Quiring, Anal. Chem., 41, 1710 (1969), 
TABLE I. BUnSEN's ABSORPTION COEFFiCIENT For $\mathrm{CO}_{2}$ IN INOSINE FERMENTATION

\begin{tabular}{llll}
\hline Kind of solution & Method & $20^{\circ} \mathrm{C}$ & $30^{\circ} \mathrm{C}$ \\
\hline Water & Titration & 0.865 & 0.670 \\
Water & Manometry & 0.865 & 0.670 \\
Medium & -do- & 0.810 & 0.615 \\
Cultured for 6 hr & -do- & 0.800 & 0.600 \\
Cultured for 2t hr & -do- & 0.790 & 0.590 \\
Cultured for 60hr & -do- & 0.775 & 0.580 \\
\hline
\end{tabular}

system.

The farther experiment was carried out with the purpose to find out the absolute solubility of carbon dioxide in inosine fermentation broth. Data show that Bunsen's absorption coefficient for carbon dioxide decreases as the fermentation proceeds.

2) Bicarbonate in cultured broth determined by the gas exchanged Warburg manometry

The concentration of bicarbonate ion under a given partial pressure of carbon dioxide was determined by the gas exchanged Warburg manometry described in the previous paper. The errors in this method were mainly caused by the evolution of carbon dioxide occurred by the respiration of living cells, and the $\mathrm{pH}$ change due to the formation of some metabolites after the sample solution was let out of the fermentor. The gas exchanged Warburg manometry was applied to the centrifuged cultured liquid which had no source to make error because the liquid did not contain living cells.

The sample solution for the determination was prepared by centrifugation at $7,000 \mathrm{rpm}$ for $10 \mathrm{~min}$ after the cultivation was done for a required time.

The productivity and the subjects related to the productivity were not mentioned in this paper but well fermented liquid was always used for this study.

The centrifuged cultured liquid was placed in the gas saturation unit, and a certain concentration of carbon dioxide gas was then applied. The state of equilibrium of the dissolution and dissociation of carbon dioxide was observed by a pH meter, and when the state of liquid reached to an equilibrium a few milliliters of the saturated solution was transferred to a Warburg flask.

The carbon dioxide gas of the same partial pressure at the saturation was employed for the gas exchanged operation.

According to the results shown in Fig. 1, the concentration of dissociated bicarbonate ions in inosine fermentation broth was always higher than that in the model system as it was reported previously, and the concentration of dissociated bicarbonate ions in glutamic acid fermentation broth was always lower than that in the model system. Moreover, it was interesting that the difference of the concentration of bicarbonate ion between the model liquid system and the cultured system became greater and greater as the fermentation went on.

This phenomenon was confirmed by the calculation using equations described in the previous paper. The calculation was performed by the substitution of the analytical data of $\mathrm{pH}$ change and $\mathrm{DCO}_{2}$ change for the terms of equation and the produced or absorbed carbon dioxide could be referred to the theoretical value of the converted bicarbonate ions which was occured by the addition of an acid or alkaline solution.

According to the experimental results shown in Table II, it was suggested that HendersonHasselbalch's law could not be maintained in the cultured system unless an appropriate modification had been done on equation for this calculation.

Some modification was therefore made in order to study the reasons for the disagreement of the concentration of bicarbonate ion in the cultured system and that in the model system. The index of the first stage dissociation constant for carbon dioxide was estimated by using the obtained data of bicarbonate concentration and Bunsen's absorption coefficient. 


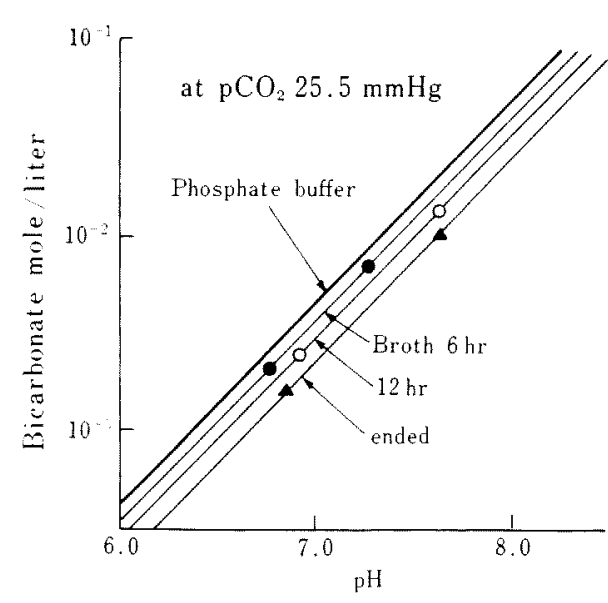

Glutamic acid fermentation

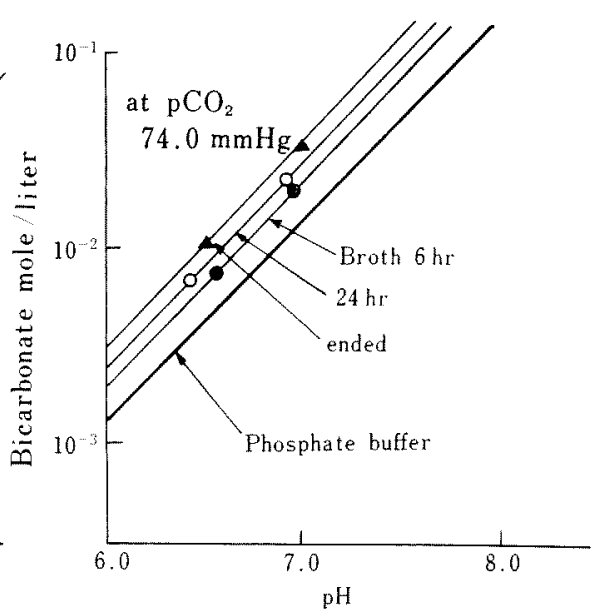

Inosine fermentation

FIG. 1. Bicarbonate Determined by Gas Exchanged Warburg Manometry.

Table II. Interconversion of Bicarbonate and Carbon Dioxide in Cultured liquid

\begin{tabular}{lcccccc}
\hline Kinds of broth & $\mathrm{pH}_{1}$ & $\mathrm{pH}_{2}$ & $\begin{array}{c}\left(\mathrm{DCO}_{2}\right)_{1} \\
\mathrm{mmHg}\end{array}$ & $\begin{array}{c}\left(\mathrm{DCO}_{2}\right)_{2} \\
\mathrm{mmHg}\end{array}$ & $\begin{array}{c}{\left[\mathrm{HCO}_{3}{ }^{-}\right]} \\
\text {mmole/liter } \\
\text { converted }\end{array}$ & $\begin{array}{c}{\left[\mathrm{HCO}_{3}{ }^{-}\right]} \\
\text {mmole/liter } \\
\text { calculated }\end{array}$ \\
\hline Inosine & 7.440 & 7.080 & 25.5 & 50.0 & 3.20 & 1.83 \\
Glutamic acid & 7.970 & 7.561 & 25.5 & 57.0 & 3.40 & 5.35 \\
-do- & 7.922 & 7.385 & 26.2 & 68.5 & 5.40 & 9.50 \\
\hline
\end{tabular}

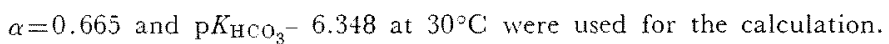

Experiment and calculation were performed by the method described in the previous paper.

The fundamental relationship between the dissociation constant and the quantity of each ingredient is given in the following equation,

$$
\mathrm{K}_{\mathrm{HrCO}_{3}{ }^{-}}=\frac{\left[\mathrm{H}^{-}\right] \cdot \gamma_{\mathrm{H}} \cdot\left[\mathrm{HCO}_{3}{ }^{-}\right] \cdot \gamma_{\mathrm{HCO}_{3}}^{-}}{\left[\mathrm{COO}_{2}\right]}
$$

where $\gamma_{н}$ is the activity coefficient of hydrogen ion and $\gamma_{\mathrm{HCO}}$ is that of bicarbonate ion. Changing both sides into logarithms, the above equation is converted as follows.

$$
\begin{aligned}
\mathrm{pK}_{\mathrm{HCO}_{-}^{-}}= & \log \left[\mathrm{CO}_{2}\right]-\log \left[\mathrm{HCO}_{3}{ }^{-}\right] \\
& -\log { }_{7 \mathrm{HCO}_{3}}+\mathrm{pH}
\end{aligned}
$$

Substituting Henry's law for $\left[\mathrm{CO}_{2}\right]$, the above equation is expressed in the function of the partial pressure of carbon dioxide in gas phase and $\mathrm{pH}$.

$$
\begin{aligned}
\mathrm{p} K_{\mathrm{HCO}_{3}}{ }^{-}= & \log \mathrm{pCO}_{2}+\log \alpha-4.231 \\
& -\log \left[\mathrm{HCO}_{3}{ }^{-}\right]-\log \gamma_{\mathrm{HCO}_{3}{ }^{-}-\mathrm{pH}}
\end{aligned}
$$

On the other hand, the logarithm of the activity coefficient is given as the following equation according to the Debye-Huckel's limiting law. ${ }^{101}$

$$
-\log \gamma \mathrm{HCO}_{3}^{-}=\frac{A \cdot Z i \cdot \sqrt{I}}{1+B \cdot \mathrm{a} \cdot \sqrt{I}}
$$

where $A$ and $B$ are constants, $Z i$ is the number of electric charge of bicarbonate ion, $I$ is the ionic strength and $a$ is the mean diameter of

10) P. Debye and E. Hückel, Physik. Z., 24, 185 (1923). 
Table III. Dissoctation Constant for Carbon Dioxide Computed by Determined [HCO ${ }^{-}$] And $\alpha$

\begin{tabular}{|c|c|c|c|c|c|}
\hline Kinds of solution & $\mathrm{O}_{3}-$ mmole liter & $\gamma \mathrm{HCO}_{3}^{-}$ & $\mathrm{p} K^{\prime}$ & $\alpha$ & $\mathrm{pK}_{\mathrm{HCO}_{3}-}$ \\
\hline Phosphate buffer & 13.50 & 0.980 & 10.749 & 0.670 & 6.344 \\
\hline Inosine fermentation medium & $18.00^{\mathrm{mi}}$ & 0.975 & 10.627 & 0.615 & 6.185 \\
\hline Cultured for $6 \mathrm{hr}$ & $19.00^{a}$ & 0.974 & 10.602 & 0.600 & 6.149 \\
\hline Cultured for $24 \mathrm{hr}$ & $20.00^{a}$ & 0.973 & 10.569 & 0.590 & 6.109 \\
\hline Cultured for $60 \mathrm{hr}$ & $23.00^{a}$ & 0.970 & 10.519 & 0.580 & 6.051 \\
\hline Glutamic acid fermentation medium & $4.70^{b}$ & 0.985 & 10.751 & 0.670 & 6.346 \\
\hline Cultured for $6 \mathrm{hr}$ & $3.60^{b}$ & 0.987 & 10.865 & 0.670 & 6.460 \\
\hline Cultured for $12 \mathrm{hr}$ & $3.00^{61}$ & 0.988 & 10.944 & 0.670 & 6.539 \\
\hline Cultured for $36 \mathrm{hr}$ & $2.40^{b i}$ & 0.989 & 11.040 & 0.670 & 6.635 \\
\hline
\end{tabular}

a) Bicarbonate determined under $\mathrm{pCO}_{2} 74.0 \mathrm{mmHg}$ at $\mathrm{pH} 7.0$.

b) Bicarbonate determined under $\mathrm{pCO}_{2} 26.5 \mathrm{mmHg}$ at $\mathrm{pH} 7.0$.

bicarbonate ion. ${ }^{11}$ Substituting the above expression for equation (11), the following relationship is obtained.

$$
\begin{gathered}
\mathrm{pK}_{\mathrm{ECO}_{3}-}-\log \alpha+4.231=\log \mathrm{pCO}_{2}+\mathrm{pH} \\
-\log \left[\mathrm{HCO}_{3}{ }^{-}\right]+\frac{A \cdot Z i \sqrt{I}}{1+B \mathrm{a} \sqrt{I}}
\end{gathered}
$$

All the members of the left side of equation (13) are constants and if $\mathrm{p} K^{\prime}$ is used for the sum of them, the above equation is expressed as follows.

$$
\begin{gathered}
\mathrm{pK}_{\mathrm{HCO}_{3}{ }^{-}=\mathrm{p} K^{\prime}-4.231+\log \alpha} \\
\mathrm{pK}^{\prime}=\log \mathrm{pCO}_{2}+\mathrm{pH}-\log \left[\mathrm{HCO}_{3}{ }^{-}\right]+\frac{A \cdot Z i \sqrt{I}}{1+B \mathrm{a} \sqrt{I}} \\
=\log \mathrm{pCO}_{2}+\mathrm{pH}-\log \left[\mathrm{HCO}_{3}{ }^{-}\right]-\log 7 \mathrm{HCO}_{3}^{-}
\end{gathered}
$$

According to the above relationships, $\mathrm{p} K^{\prime}$ is calculated if $\mathrm{PCO}_{2}$ and $\mathrm{pH}$ are known and the concentration of bicarbonate ion is determined. Table III shows these results obtained from the calculation.

In this calculation, however, the activity coefficient of bicarbonate ion was used for the term of $I$.

The data show that index of dissociation constants seemed to be varied depending upon

11) R. A. Robinson and R. H. Stokes, "Electrolyte Solutions," Butterworths (London), 1965. the kind of fermentation and the period of fermentation time.

3) Fixation of bicarbonate ion by Millipore Filter

A good result was obtained in centrifugal broth, but the actual concentration of bicarbonate ion of cultured liquid in the fermentor could not be regarded as exactly the same as the concentration obtained from the centrifugal sample. In order to determine the real amount of dissociated bicarbonate ions in the cultured system, the instantaneous filtration was developed by using the Millipore Filter with the micro syringe filter holder. Even though living cells were removed by filtration, it was still impossible to maintain the same partial pressure of carbon dioxide before and after the sampling operation, and during the time of the sample preparation. It was impossible to fade completely interconvertion of bicarbonate and carbon dioxide even $\mathrm{pH}$ value was maintained at the constant level as precisely as possible.

The removal of living cells depressed the variation of $\mathrm{pH}$ value but there was still the problem of causing errors. The difference of the partial pressure of carbon dioxide between the liquid in the fermentor and the sample solution made the variation of the concentration of bicarbonate ion.

The phosphate buffer solution was employed 


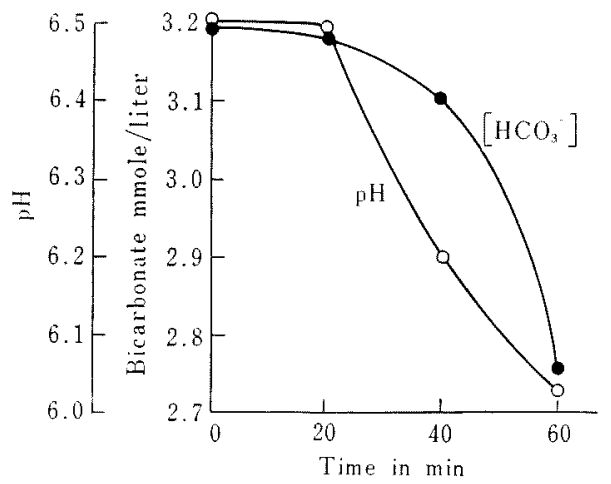

FIG. 2. The Stability of Bicarbonate Ion in Cultured Liquid.

in this study and carbon dioxide gas was flown into the apparatus which was illustrated in the previous paper. A little amount of carbon dioxide saturated solution was then taken out of the vessel and stood for a given minutes under atmospheric circumstances. The quantity of formed bicarbonate ions was determined by the Warbung manometry. The results are shown in Fig. 2 and it was found that the bicarbonate ion concentration did not decrease rapidly, even no countermeasure to depress the dispersion of gaseous carbon dioxide was undertaken.

A good approximation was obtained on the results between the gas exchanged Warburg method and Warburg direct method as far as the operation of determination would be finished within one half of an hour after the sampling operation. The quantity of bicarbonate ion at zero time in Fig. 2 was determined by the gas exchanged Warburg manometry because the result obtained by this method was regarded as the most reliable value.

The result of the Warburg direct method agreed with the result of the gas exchanged Warburg method and it was interpreted by the study of the kinetics of the reaction from carbon dioxide to bicarbonate ion.

According to the result reported by F. J.W. Roughton, the reaction of the dissolution and dissociation of carbon dioxide is classified into the following two steps.

$$
\begin{aligned}
& \mathrm{CO}_{2}+\mathrm{H}_{2} \mathrm{O} \underset{k_{32}}{\stackrel{k_{23}}{\leftrightarrows}} \mathrm{H}_{2} \mathrm{CO}_{3} \\
& \mathrm{H}_{2} \mathrm{CO}_{3} \stackrel{k_{k_{43}}}{\leftrightarrows} \mathrm{H}^{+}+\mathrm{HCO}_{3}^{-}
\end{aligned}
$$

The first stage reaction indicated in equation (16) was considered to be of definite time course and the second stage reaction expressed in equation (17) was considered to be instantaneous. The velocity constants of equation (16) were obtained as $2 \times 10^{-3} \mathrm{M}^{-1}, \sec ^{-1}$ for $k_{23}$ and $2.0 \mathrm{sec}^{-1}$ for $k_{32}$ respectively ${ }^{12,13)}$ at $0^{\circ} \mathrm{C}$. On the other hand, the velocity constants of equation (17) were very large, $k_{34}$ was probably the order of $10^{7} \mathrm{sec}^{-1}$ and $k_{43}$ was the order of $5 \times 10^{10} \mathrm{M}^{-1}, \mathrm{sec}^{-1}$. ${ }^{14}$ It was therefore said that the velocity of the reaction from bicarbonate ion to carbon dioxide was slower than that from carbon dioxide to bicarbonate ion.

If living cells were completely removed by filtration, the respiration of cultured broth was almost perfectly depressed. Neither production of carbon dioxide nor absorption of oxygen was observed on the filtered broth by the Warburg manometry, while a great amount

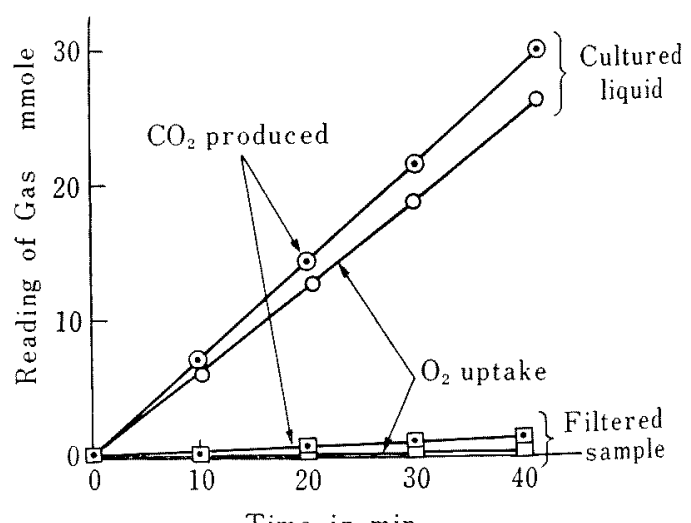

Time in $\mathrm{min}$

FIG. 3. Suspension of Respiration by Filtration.

12) B. R. W. Pinsent, L. Pearson and F. J. W. Roughton, Trans. Faraday Soc., 52, 1512 (1956).

13) J.A. Sirs, ibid., 54, 201 (1958).

14) M. Eigen, K. Kustin and G. Maass, Z. Physik. Chem., 30, 130 (1961). 
Table IV. Warburg Manometry for Filtered Broth and the Warburg Direct Method

\begin{tabular}{clccc}
\hline $\begin{array}{c}\text { Experimental } \\
\text { No. }\end{array}$ & Method & $\begin{array}{c}\mathrm{pCO}_{2} \\
\text { atm. }\end{array}$ & $\mathrm{pH}$ & $\begin{array}{c}\left.\text { [HCO }_{3}{ }^{-}\right] \\
\text {mmole/liter }\end{array}$ \\
\hline I & Direct & 0.100 & 6.75 & 16.10 \\
& Filtered & 0.100 & 6.75 & 15.40 \\
II & Direct & 0.120 & 6.50 & 10.70 \\
& Filtered & 0.120 & 6.50 & 10.70 \\
III & Direct & 0.070 & 6.50 & 3.80 \\
& Filtered & 0.070 & 6.50 & 3.80 \\
\hline
\end{tabular}

Broth of inosine fermentation was used.

of carbon dioxide evolution and oxygen uptake were confirmed on the cell containing sample.

This fact was demonstrated in Fig. 3 and there was no doubt that bicarbonate ions in the cultured system could be preserved in the filtrated liquid with the state of equilibrium of dissociation for carbon dioxide.

The respiration inhibitors such as potassium cyanide, sodium arsenate and $p$-chloromercuribenzoic acid as well as the usage of potassium hydroxide solution showed a weak activity to stop the respiratory action immediately.

Thus the filtration method had many advantages to determine the concentration of bicarbonate ion of cultured liquid but this method still had a defect that the determination was done without living cells. In order to diminish this defect, the direct determination method was developed.

The cultured broth with bacterial cells was placed in a Warburg flask and the respiration of living cells was left to continue in the flask as well as in the fermentor. When the temperature came to equilibrium, all bicarbonate ions would be exhaled as gaseous carbon dioxide by the addition of the sulfuric acid solution. This method was applied to inosine fermentation broth cultured for $24 \mathrm{hr}$. The concentration of bicarbonate ions at various hours of culturing time was being compared in two different ways, the Warburg direct method and the Warburg monometry for filtered sample.

The results are shown in Table IV and those two method gave a satisfactory agreement.

Acknowledgement. The authors wish to express their sincere thanks to Dr. Motoyoshi Hongo, Professor of the University of Kyushu, for his continuing guidance and encouragement. 